\title{
Microstructural Evolution and Mechanical Properties of Hybrid Bevel Gears Manufactured by Tailored Forming
}

\author{
Bernd-Arno Behrens ${ }^{1}$, Anna Chugreeva ${ }^{1, *}$, Julian Diefenbach ${ }^{1}$, Christoph Kahra ${ }^{2}$, \\ Sebastian Herbst ${ }^{2}\left(\mathbb{D}\right.$, Florian Nürnberger ${ }^{2}\left(D\right.$ and Hans Jürgen Maier ${ }^{2}(\mathbb{D}$ \\ 1 Institut für Umformtechnik und Umformmaschinen (Forming Technology and Machines), \\ Leibniz Universität Hannover, 30823 Garbsen, Germany; behrens@ifum.uni-hannover.de (B.-A.B.); \\ diefenbach@ifum.uni-hannover.de (J.D.) \\ 2 Institut für Werkstoffkunde (Materials Science), Leibniz Universität Hannover, 30823 Garbsen, Germany; \\ kahra@iw.uni-hannover.de (C.K.); herbst@iw.uni-hannover.de (S.H.); \\ nuernberger@iw.uni-hannover.de (F.N.); maier@iw.uni-hannover.de (H.J.M.) \\ * Correspondence: chugreeva@ifum.uni-hannover.de; Tel.: +49-51176218280
}

Received: 17 September 2020; Accepted: 8 October 2020; Published: 13 October 2020

\begin{abstract}
The production of multi-metal bulk components requires suitable manufacturing technologies. On the example of hybrid bevel gears featuring two different steels at the outer surface and on the inside, the applicability of the novel manufacturing technology of Tailored Forming was investigated. In a first processing step, a semi-finished compound was manufactured by cladding a substrate using a plasma transferred arc welding or a laser hotwire process. The resulting semi-finished workpieces with a metallurgical bond were subsequently near-net shape forged to bevel gears. Using the residual heat after the forging process, a process-integrated heat treatment was carried out directly after forming. For the investigations, the material combinations of 41Cr4 with C22.8 (AISI 5140/AISI 1022M) and X45CrSi9-3 with C22.8 (AISI HNV3/AISI 1022M) were applied. To reveal the influence of the single processing steps on the resulting interface, metallographic examinations, hardness measurements and micro tensile tests were carried out after cladding, forging and process-integrated heat treatment. Due to forging and heat-treatment, recrystallization and grain refinement at the interface and an increase in both, hardness and tensile strength, were observed.
\end{abstract}

Keywords: hybrid components; bevel gears; hot forging; tailored forming; process-integrated heat treatment; air-water spray cooling; self-tempering

\section{Introduction}

The material choice for conventional monolithic components, commonly used in bulk metal forming at industrial scale, represents a compromise between material properties and economical requirements [1]. In parts with locally varying mechanical, thermal or chemical operating conditions, it is rather challenging to identify a single material, which fulfils the individual specifications. Increasing demands on technical components due to current trends towards resource and energy efficiency render this issue even more difficult and have triggered the development of alternative technological solutions to overcome the material-specific restrictions. In this context, multi-material (hybrid) designs combining the benefits of different materials in a single component offer a great potential for creating high-performance components with extended functionality and resource efficiency [2]. While this concept is well-established in the sheet metal industry (tailored blanks [3] or clad rolling [4,5]), further research is required in bulk metal forming, e.g., for hot forging processes. Specifically, 
the development of novel technologies for manufacturing metallic multi-material parts is required. The Collaborative Research Centre 1153 investigates the innovative process chain of Tailored Forming to manufacture hybrid metallic high-performance components by hot or semi-hot forming of prior joined preforms. Combinations of different joining and forming processes are evaluated on the example of technical parts such as bearing washers [6], bearing bushings [7] and transmission shafts [8]. In the following, the hot forging of hybrid metal bevel gears from cladded preforms made of two different steel grades combined with a subsequent process-integrated heat treatment are presented. The investigations involve an analysis of the interface using metallographic examinations before and after forming as well as after the integrated heat treatment. For a quantitative characterization of the bond quality, tensile tests were conducted using micro tensile samples and hardness values were measured.

\section{State of the Art}

Forging is a key technology for manufacturing technical components with complex geometries and provides for continuous fiber flow and excellent mechanical properties. Depending on the initial state of the applied semi-finished parts, there are two methods of forming multi-material components: compound and hybrid forging. In compound forging, raw parts assembled without a metallurgical bond are used. The joining of these parts takes place during forming to the end geometry. The challenge in joining by forming is to create a metallurgical bond between the different materials. In compound forging, the focus is often on parameter case studies in order to achieve a sufficient bond quality, as the latter depends on specific process conditions such as temperature, contact pressures and relative displacement between the materials. For example, Sun et al. studied a hot isothermal compression bonding process of two different steel grades (Q235 and $316 \mathrm{~L})$ using experimental and numerical investigations. They found that the element diffusion distance in the near interface zone grows with increasing deformation temperatures, effective strains and holding times. However, increasing effective strain rates have a negative impact on bond quality [9]. Investigations of Kong et al. on the forge welding of steel-aluminum compounds (AISI $316 \mathrm{~L} / 6063$ aluminum) reveal that the forming temperature has the highest influence on the resulting bond quality and the tensile strength of the joint [10]. Wohletz and Groche studied a joining process combining forward and cup extrusion for manufacturing steel-aluminum parts (AISI 1015/6082 T6 aluminum) [11]. They observed that an increased formation of oxide scale on the contact surfaces at elevated temperatures has a negative influence on the resulting bond quality. Due to the above-mentioned restrictions, which result in a narrow range of suited possible process parameters, it is difficult to ensure a homogeneous bond quality when forming hybrid parts with complex geometry, process-related variation in strains and non-uniform material flow. In such a case, the application of previously joined semi-finished parts featuring a metallurgical bond is advantageous for achieving uniform characteristics at the interface. This approach, called hybrid forging, aims at improving the microstructure and the mechanical properties of the material compound. For instance, Förster et al. investigated a two-step forging process of aluminum-enclosed magnesium work pieces, which had previously been joined by co-extrusion [12]. After forging, the magnesium core was crack-free and fully enclosed by aluminum, even at the front ends of the prior extruded, initially aluminum-free profile sections. Though in these regions no metallurgical bond was observed, the bonding achieved by extrusion was maintained. Domblesky et al. conducted axial and side compression tests of friction-welded workpieces with a serial arrangement made from the same materials or material combinations (copper, steel, aluminum) [13]. All material combinations demonstrated a good workability during the forming stage. For combinations of identical materials, the tensile tests showed uniform deformation and material flow similar to that of monolithic materials. In the case of dissimilar material combinations, most of the deformation and subsequent fracture occurred in the softer metal. Klotz et al. performed an isothermal forging of bi-metal gas turbine discs made of two different Ni-based superalloys from hot isostatically pressed billets [14]. They found that bond quality after forming depends on the initial state of the hot isostatically pressed 
preforms. The formed specimens showed a refined microstructure due to recrystallization at hot forming temperatures.

If the hot-forged steel parts feature a near-net-shape geometry and the temperature after forming is in the austenite regime, a quenching and tempering can be carried out directly after hot forming [15]. Such an integration of the heat treatment into the hot-forming process is used to reduce process costs and times. By applying a controlled cooling with an air-water spray, locally adapted cooling rates can be achieved ranging from low cooling rates as in gas quenching up to high cooling rates as in immersion cooling in water [16]. In addition, the quenching process can be interrupted in order to self-temper the hardened surface using the residual heat remaining in the core of the component. By spray cooling, a continuous and gentle hardness transition is achievable, which can be favorable regarding stress distribution compared to parts featuring a steep hardness gradient [17]. Hence, the near-net shape Tailored Forming of bevel gears in combination with spray cooling offers the potential to manufacture parts with a high fatigue strength and extended service life.

\section{Materials and Methods}

\subsection{Initial Geometry}

Hybrid designs can be beneficial for all technical components that experience different loads throughout the part. Accordingly, it is favorable to place high-performance materials in highly stressed areas, while the remaining structural areas can be made of lightweight or low-cost materials. In the following, the Tailored Forming of a bevel gear combining two different steel grades is discussed. For the contacting tooth flanks exposed to rolling loads under operating conditions, a high-strength steel 41Cr4 (1.7035-AISI 5140) and a martensitic valve steel X45CrSi9-3 (1.4718-AISI HNV3) were used. The core of the bevel gear consisted of the low-alloyed steel C22.8 (1.0460-AISI 1022M). According to the assumed load collective, the coaxially arranged hybrid workpieces were produced by two different types of weld cladding: plasma transferred arc deposition welding (PTAW) and laser hotwire cladding (LHC). The corresponding cladded preforms are shown in Figure 1a,b.

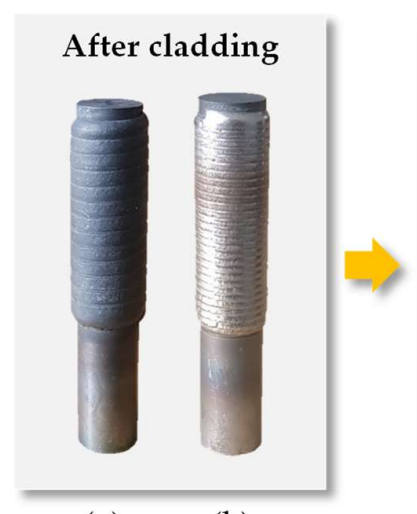

(a)

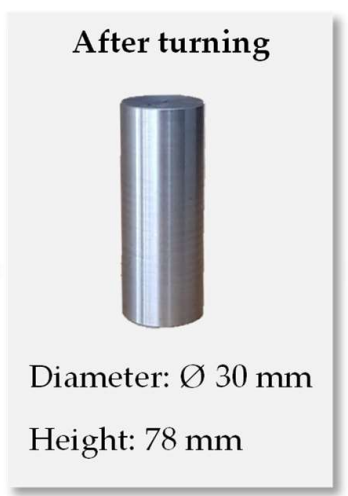

(c)

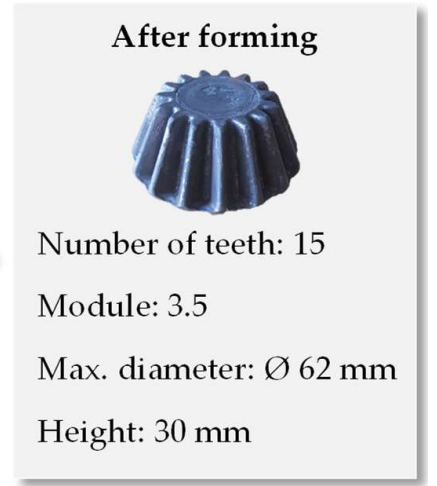

(d)

Figure 1. Cladded preforms produced with plasma transferred arc deposition welding (PTAW) (a) and laser hotwire cladding (LHC) (b) using a substrate with a diameter of $27 \mathrm{~mm}$; geometry of the turned workpiece (c) and bevel gear (d).

For both methods, the cladding was welded onto a rotating cylinder of the C22.8 substrate. Due to the simultaneous axial movement of the cylinder, the weld seams formed a spiral pattern, which resulted in a wavy contour of the joining zone and non-uniform thickness of the clad layer as shown in a longitudinal cross section in Figure 2. Its thickness depends on the width of the sealing seams and the welding penetration depth, which differ according to the cladding method. Based on recommended thickness values determined in prior investigations on the compound forging of cylindrical gears, the diameter of the substrate cylinders was set to $\varnothing 27$ and $\varnothing 28 \mathrm{~mm}$ for PTAW [18]. A smaller 
diameter is not suitable due to the high heat input during cladding. For these specimens, the material combination C22.8 (substrate)/41Cr4 (cladding) was used. For the LHC process, a substrate diameter of $\varnothing 27 \mathrm{~mm}$ was favorable to achieve the minimal required thickness of the clad layer but prevent a cladding with several overlapping layers. In this case, a combination of C22.8 (substrate)/X45CrSi9-3 (cladding) was investigated. In order to ensure a constant diameter of the part, the cladded workpieces were additionally turned to a diameter of $\varnothing 30 \mathrm{~mm}$ and shortened to a length of $78 \mathrm{~mm}$ (Figure 1c). The geometry of the hybrid bevel gear is illustrated in Figure 1d).

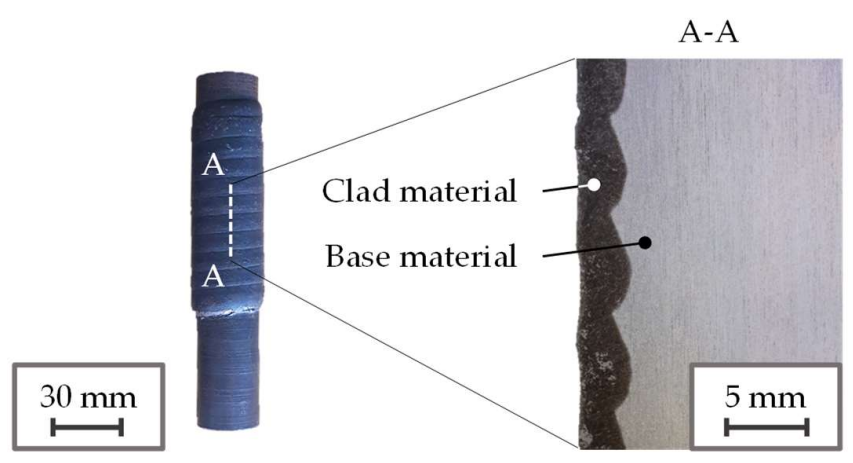

Figure 2. Material distribution in plasma transferred arc (PTA) cladded workpiece for a 41Cr4/C22.8 combination with an initial substrate diameter of $\varnothing 27 \mathrm{~mm}$ along the cutting line A-A (longitudinal cross section).

\subsection{Die Forging}

The hybrid workpieces were used to form the near-net-shaped geometry of the bevel gear. The forging experiments were carried out on a screw press Lasco SPR 500 (LASCO Umformtechnik $\mathrm{GmbH}$, Coburg, Germany) with a maximum capacity of $40 \mathrm{~kJ}$ per single step. The corresponding forming tool system depicted in Figure 3 was designed modularly. The lower die and the upper geared die are the main components, creating the mold. The geared die is located in the upper part of the tool. This ensures an appropriate detaching of the final forgings by their own weight. The height of the bevel gear is defined by limit stops. Before forming, the forging dies were heated up to a temperature of $200{ }^{\circ} \mathrm{C}$. The maximum forging force was approx. $510 \mathrm{kN}$.

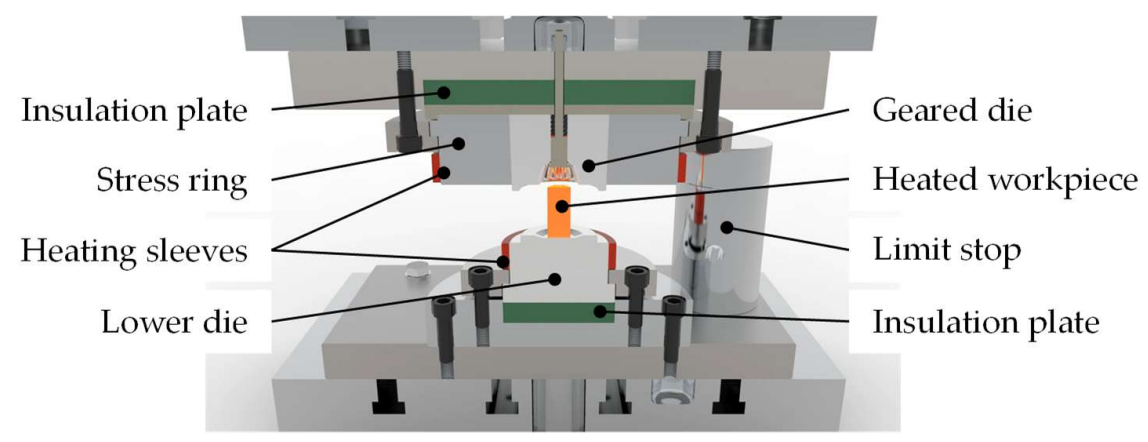

Figure 3. Forging tool system for manufacturing hybrid bevel gears.

The heating of the workpieces was carried out inductively. For an optimal die filling, an axially inhomogeneous heating profile was used (Figure 4). Details about the heating strategy are given in [19]. An axial temperature gradient of ca. $200{ }^{\circ} \mathrm{C}$ was achieved by off-center positioning of the workpiece inside the induction coil. By means of the electromagnetic end effect occurring in the workpiece areas located close to the edge of the induction coil, it was possible to set lower temperatures in the lower part of the workpiece [20]. In order to ensure high reproducibility of the forging tests, the pre-heated workpieces were automatically transferred from the induction coil to the forging tool system. After forging, the bevel gears were directly transported to the air-water spray cooling station 
and subsequently processed in an integrated heat treatment step. In the reference process route without heat treatment, the bevel gears were cooled in still air.

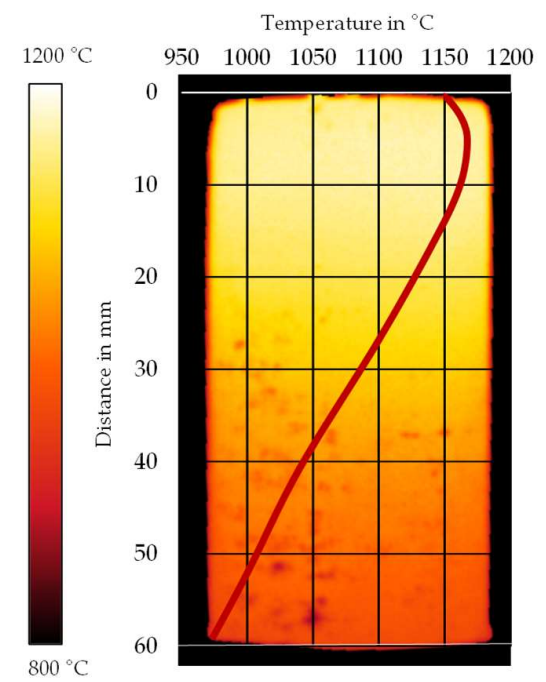

Figure 4. Thermographic image and axial temperature profile measured at the workpiece surface before forming.

\subsection{Heat Treatment}

The forming process was followed by a process-integrated surface hardening by quenching using an air-water spray cooling (Figure 5). The residual heat in the bevel gear after forging was employed for process-integrated heat treatment. By applying a short intensive cooling, a martensitic surface layer was formed; by interrupting the intensive cooling after a given time, a subsequent self-tempering of this surface layer was realized. This self-tempering of the martensitic surface layer occurs when residual heat from the core of the not fully quenched bevel gear flows to the surface.

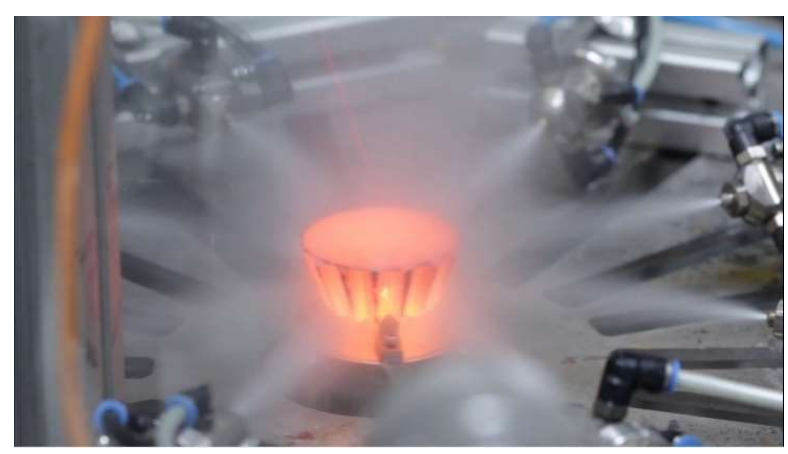

Figure 5. Quenching of a rotating bevel gear in an air-water spray.

The spray cooling system consisted of eight air-water spray nozzles (Internal Mix Nozzles, SUJ12, Spraying Systems $\mathrm{Co}^{\circledR}$, Wheaton, IL, USA) annularly arranged around a rotating mount for the bevel gear. The nozzles were aligned at a distance of $100 \mathrm{~mm}$ from the workpiece surface. By varying air and water inlet pressures, the cooling rate was adjusted. A martensitic surface layer in the toothing area of the bevel gears was produced by a short quenching phase with high cooling rates. Subsequently, the residual heat remaining in the core of the bevel gear was employed to temper the surface layer. By means of employing active cooling, the self-tempering temperature could be controlled. A pyrometer was used to monitor the set self-tempering temperature. The pyrometer recorded the temperature at the tooth tip during the self-tempering phase. Since air-water spray was employed during self-tempering, measurement was only possible between two air-water spray pulses. Hence, short pulses of air-water spray were employed automatically every time the surface 
temperature exceeded the desired self-tempering temperature. To ensure a uniform heat treatment start temperature after transporting the forged bevel gears from the forging press to the spray cooling system, a second pyrometer measured the temperature on the top side of the bevel gear. By means of numerical simulations of process-integrated surface hardening and tempering, the spray parameters (inlet pressures), the duration of the quenching phase and the self-tempering temperature were determined; see Table 1. The heat transfer coefficients for the simulation were estimated by prior cooling tests on bevel gears. To compute the cooling curves by numerical simulations of the quenching process, boundary conditions were adapted as described in [21].

Table 1. Heat treatment parameters of the different hybrid bevel gears.

\begin{tabular}{|c|c|c|}
\hline Material Combination & $41 \mathrm{Cr} 4,41 \mathrm{Cr} 4 / \mathrm{C} 22.8, \varnothing 27$ and $\varnothing 28 \mathrm{~mm}$ & $\mathrm{X} 45 \mathrm{CrSi} 9-3 / \mathrm{C} 22.8$, Ø $27 \mathrm{~mm}$ \\
\hline Start temperature & $950^{\circ} \mathrm{C}$ & $1000^{\circ} \mathrm{C}$ \\
\hline Duration 1st phase & $10 \mathrm{~s}$ & $8 \mathrm{~s}$ \\
\hline Cooling medium 1st phase & Air-water spray & Air-water spray \\
\hline Tempering temperature 2 nd phase & $300^{\circ} \mathrm{C}$ & $750^{\circ} \mathrm{C}$ \\
\hline Cooling medium 2nd phase & Air-water spray & Air-water spray \\
\hline
\end{tabular}

Figure 6 shows the time-temperature curves recorded during heat treatment of the bevel gears with a first phase of quenching followed by the self-tempering phase. The temperatures were measured at the tooth flanks with a pyrometer and used to control the self-tempering process. If the specified self-tempering temperature of $300{ }^{\circ} \mathrm{C}$ in the bevel gears with the material combination $41 \mathrm{Cr} 4 / \mathrm{C} 22.8$ was exceeded, the air-water spray pulse was activated for a short period to reduce surface temperature. This resulted in temperature oscillations (green and orange curves) during the tempering phase starting at about $15 \mathrm{~s}$. Due to the higher recommended self-tempering temperatures of up to $750{ }^{\circ} \mathrm{C}$ for the steel $\mathrm{X} 45 \mathrm{CrSi} 9-3$, no air-water spray cooling was required in this heat treatment phase; hence, for the material combination $\mathrm{X} 45 \mathrm{CrSi} 9-3 / \mathrm{C} 22.8$, no such cooling related oscillations occurred. Instead, only oscillations with lower amplitude are visible caused by the rotation of the bevel gears during heat treatment. The system was manually stopped when an active control of the tempering temperature was no longer required, so that the total self-tempering times seen in Figure 6 vary. The sudden temperature drop at the end of each plot is caused by stopping the measurement. After self-tempering, the bevel gears were placed outside of the spray cooling arrangement and cooled down in still air.

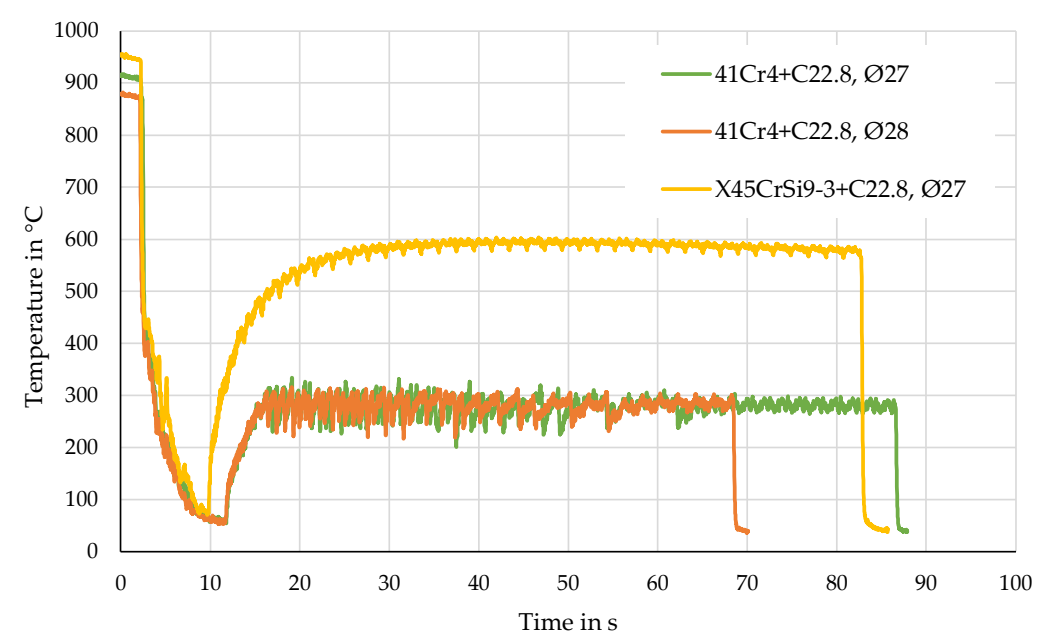

Figure 6. Temperature curves measured with a pyrometer at the tooth flank of the bevel gear.

\subsection{Investigation of the Joining Zone}

To characterize the microstructural evolution after each process step, cross-sections were extracted from the hybrid workpieces and the bevel gears. Due to deviating forming temperature and strain 
distribution in the upper and in the lower part of the bevel gear, two sampling positions $\mathrm{A}$ and $\mathrm{B}$ were employed (Figure 7a). After metallographic preparation, the specimens were etched with 5\% nitric acid solution. To reveal the martensitic microstructure of the X45CrSi9-3 steel, an etching with Beraha II reagent was applied to the cladded and forged samples, and a V2A etchant was used on the heat-treated specimens. A detailed microstructural analysis of the combination X45CrSi9-3/C22.8 is given in [19]. Hardness measurements according to Vickers (HV0.5) were carried out for both the cladding layer and the substrate close to the interface [22]. In the bevel gears, the hardness was examined in the tooth tip area. The average values and the standard deviations given in Table 2 were calculated based on 10 indentations each in the cladding layer and in the substrate.

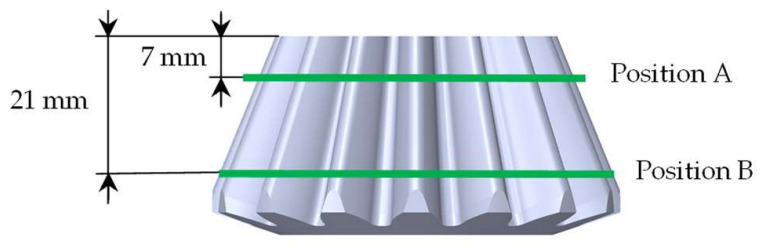

(a)

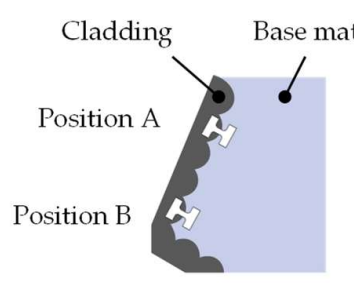

(c)

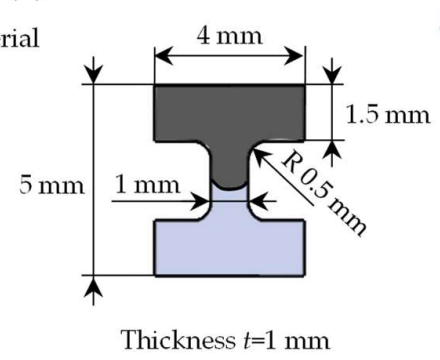

(d)

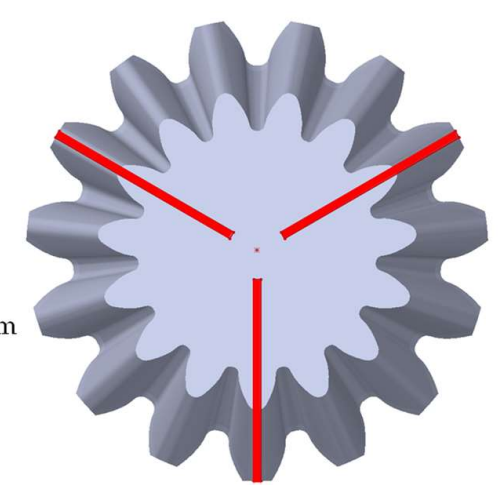

(b)

Figure 7. Sampling positions of the cross-sectional micrographs for metallographic examination and hardness measurements (a), extraction position of the sample plates (b), extraction position of the tensile specimens from the sample plates (c), geometry of the micro tensile specimen (d).

Table 2. Average hardness values (HV 0.5) of cladding and substrate after cladding, forging and heat treatment.

\begin{tabular}{|c|c|c|c|c|c|}
\hline \multicolumn{3}{|c|}{ Material Combination } & \multirow{3}{*}{$\begin{array}{c}\begin{array}{c}\text { 41Cr4/C22.8, } \\
\text { Ø27 mm }\end{array} \\
299 \pm 16 \\
164 \pm 7\end{array}$} & \multirow{3}{*}{$\begin{array}{c}\begin{array}{c}\text { 41Cr4/C22.8, } \\
\text { Ø28 mm }\end{array} \\
289 \pm 13 \\
165 \pm 13\end{array}$} & \multirow{3}{*}{$\begin{array}{c}\text { X45CrSi9-3/C22.8, } \\
\text { Ø27 mm } \\
379 \pm 13 \\
146 \pm 3\end{array}$} \\
\hline Claddes & kniece & Cladding layer & & & \\
\hline \multirow{5}{*}{ After forging } & & Substrate & & & \\
\hline & \multirow{2}{*}{ Position A } & Cladding layer & $221 \pm 9$ & $262 \pm 8$ & $462 \pm 77$ \\
\hline & & Substrate & $170 \pm 3$ & $166 \pm 4$ & $148 \pm 4$ \\
\hline & \multirow{2}{*}{ Position B } & Cladding layer & $224 \pm 7$ & $238 \pm 3$ & $276 \pm 4$ \\
\hline & & Substrate & $156 \pm 8$ & $152 \pm 4$ & $140 \pm 2$ \\
\hline \multirow{4}{*}{$\begin{array}{l}\text { After heat } \\
\text { treatment }\end{array}$} & \multirow{2}{*}{ Position A } & Cladding layer & $513 \pm 7$ & $539 \pm 9$ & $589 \pm 23$ \\
\hline & & Substrate & $410 \pm 6$ & $413 \pm 6$ & $268 \pm 5$ \\
\hline & \multirow{2}{*}{ Position B } & Cladding layer & $503 \pm 6$ & $534 \pm 7$ & $732 \pm 7$ \\
\hline & & Substrate & $345 \pm 12$ & $340 \pm 14$ & $188 \pm 3$ \\
\hline
\end{tabular}

For a mechanical characterization of the interface, tensile test specimens with the geometry given in Figure 7d were cut from the longitudinal cross section of the cladded workpieces and the hybrid bevel gears using wire electrical discharge machining (EDM). The samples from the bevel gears were cut from the tooth tip area according to the sampling position depicted in Figure $7 \mathrm{~b}$. At first, three thin plates with a thickness of $1 \mathrm{~mm}$ were eroded from each section and etched with $\mathrm{FeCl}_{3}$ reagent to reveal the material distribution. Thus, the tensile specimen from both positions $\mathrm{A}$ and $\mathrm{B}$ could be prepared precisely by means of wire EDM featuring the joining zone in the center of the specimen as shown in Figure 7c. Overall, six specimens were extracted from each bevel gear and each workpiece. 
The experiments were carried out using a tensile testing machine Zwick Retro (Line ZwickRoell, Ulm, Germany) with a maximum capacity of $10 \mathrm{kN}$. Prior to testing, the specimens were pre-stressed with a load of $5 \mathrm{~N}$. The stress increase rate was set to $30 \mathrm{MPa} / \mathrm{s}$ according to standard EN ISO 6892-1 [23].

\section{Results}

The results of the microstructural examination are summarized in Figure 8. In both types of PTAW-cladded workpieces made of 41Cr4/C22.8 (Figure 8a,b), the clad material (marked as CM) shows a pearlitic microstructure with ferrite along the former austenitic grain boundaries. The base material (marked as BM) has a ferritic-pearlitic microstructure with a prevailing ferrite fraction typical for low eutectoid steels. Close to the joining zone, a needle-shaped Widmanstätten structure is visible, which is induced by the high cooling rates after the cladding process. The forging process has a positive influence by completely transforming the coarse-grained weld microstructures. A smooth transition between cladding and substrates is visible. Grain refinement by recrystallization due to thermomechanical treatment took place at both investigated positions A and B (Figure $8 \mathrm{~d}-\mathrm{h}$ ).

In the LHC workpieces combining $\mathrm{X} 45 \mathrm{CrSi} 9-3$ and $\mathrm{C} 22.8$, the cladding material $\mathrm{X} 45 \mathrm{CrSi} 9-3$ mainly consists of martensite and nodular-shaped pearlite. The substrate contains a mixture of ferrite and pearlite (Figure 8c). However, the Widmanstätten structure, which appears in the substrate close to the joining zone after cladding, is less pronounced compared to the $41 \mathrm{Cr} 4 / \mathrm{C} 22.8$ workpieces. This can be explained by lower heat input during LHC in comparison to the PTAW, resulting in a lower thickness of the heat-affected zone (HAZ). Probably, there was also some difference in the cooling rates as well as in the start temperature of the transformation. In the transition zone, a pearlite interlayer with a thickness up to $50 \mu \mathrm{m}$ can be observed, which is retained after forging.

Contrary to the $41 \mathrm{Cr} 4 / \mathrm{C} 22.8$ workpieces, the micrographs of the combination $\mathrm{X} 45 \mathrm{CrSi} 9-3-\mathrm{C} 22.8$ show some microstructural differences at positions A and B (Figure $8 \mathrm{f}-\mathrm{i}$ ). While the substrate shows grain refinement in both cases, the former austenitic grains of the cladding material have a coarser structure in position $\mathrm{A}$ than in position $\mathrm{B}$. This means that the cladding of $\mathrm{X} 45 \mathrm{CrSi}-9$ is more sensitive to the temperature gradient between lower and upper part of the bevel gear (Figure 4) and the strain differences than the cladding of $41 \mathrm{Cr} 4$. The higher forming temperature at position A can result in intensive grain growth, which cannot be compensated for by recrystallization due to the lower strain at this position.

The heat treatment showed the desired impact on the microstructure in all cases. Due to the high cooling rates during spray quenching, a fully martensitic microstructure free of pearlite was achieved in both claddings. The subsequent self-tempering, applied to reduce brittleness and residual stresses in the hardened microstructure, tempers the martensite in the cladding layer as depicted in Figure 8j-0. A similar microstructure is also present in the partially heat-affected substrate close to the joining zone, providing a smooth transition between cladding and substrate. Moreover, the pearlitic interlayer observed in the material combination $\mathrm{X} 45 \mathrm{CrSi} 9-3 / \mathrm{C} 22.8$ was fully suppressed by the heat treatment.

The average hardness values given in Table 2 are in line with the microstructural features described above. The hardness values of $\mathrm{X} 45 \mathrm{CrSi} 9-3$ were in all cases higher than those of $41 \mathrm{Cr} 4$, since at least some fraction of martensite forms even for the low cooling rates when cooling in still air. For both investigated material combinations, the hardness of the substrate and of the cladding material remained at the same level after forging as after cladding. However, the heat treatment resulted in a substantial increase in the material strength, and the tempered martensite in the cladding layer showed hardness values above $500 \mathrm{HV}$ 0.5. For X45CrSi9-3, a maximum hardness of approx. $730 \mathrm{HV} 0.5$ was achieved at position B and of approx. $590 \mathrm{HV} 0.5$ at position A. This variance can be attributed to the microstructural differences observed between positions $\mathrm{A}$ and $\mathrm{B}$. 


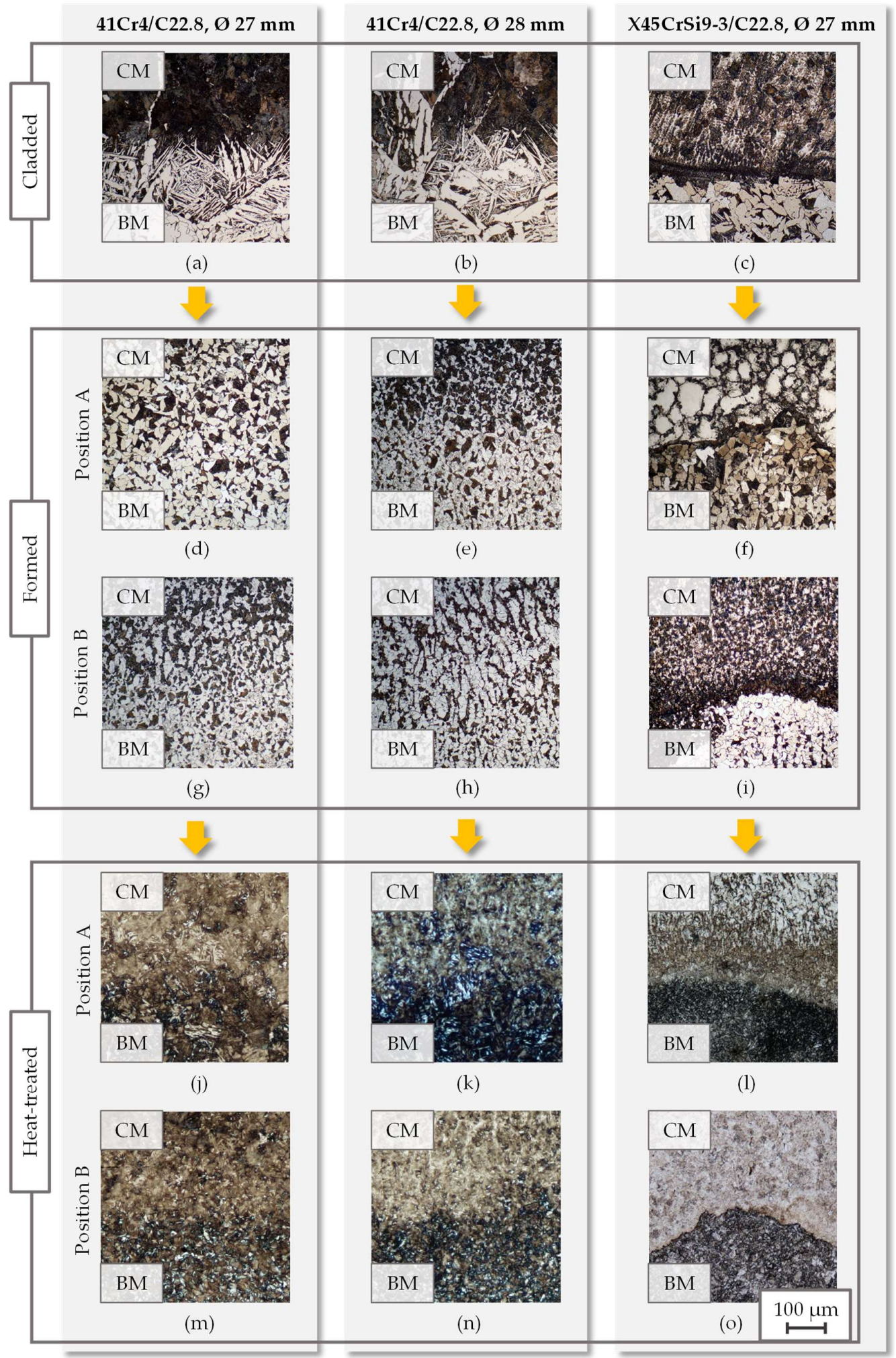

Figure 8. Microstructural evolution in the material combinations $41 \mathrm{Cr} 4 / \mathrm{C} 22.8$ and $\mathrm{X} 45 \mathrm{CrSi}-3 / \mathrm{C} 22.8$ after cladding $(\mathbf{a}-\mathbf{c})$, forming $(\mathbf{d}-\mathbf{i})$ and heat-treatment $(\mathbf{j}-\mathbf{o})$; etched with $5 \%$ nitric acid solution excluding $(\mathbf{c}, \mathbf{f}, \mathbf{i})$ — etched with Beraha II reagent—and $(\mathbf{l}, \mathbf{o})$ - Etched with V2A etchant.

The average tensile strength values for all investigated conditions are summarized in Figure 9. In all specimens, fracture in the hybrid samples occurred within the gauge section on the side of the base material with the lower strength. Thus, the measured values are not labeled as bond strength 
but as tensile strength. In analogy to the hardness values, the strength values for the conditions after cladding and after forming show no substantial differences (Figure 9a-c), and the strength values at positions A and B are similar. The values for mono-material specimens made of $41 \mathrm{Cr} 4$ (marked grey) are considerably higher after forming than those of the hybrid specimens. This can be attributed to the elevated mechanical properties of the steel $41 \mathrm{Cr} 4$ in comparison to the C22.8 substrate, in which all hybrid specimens fractured.

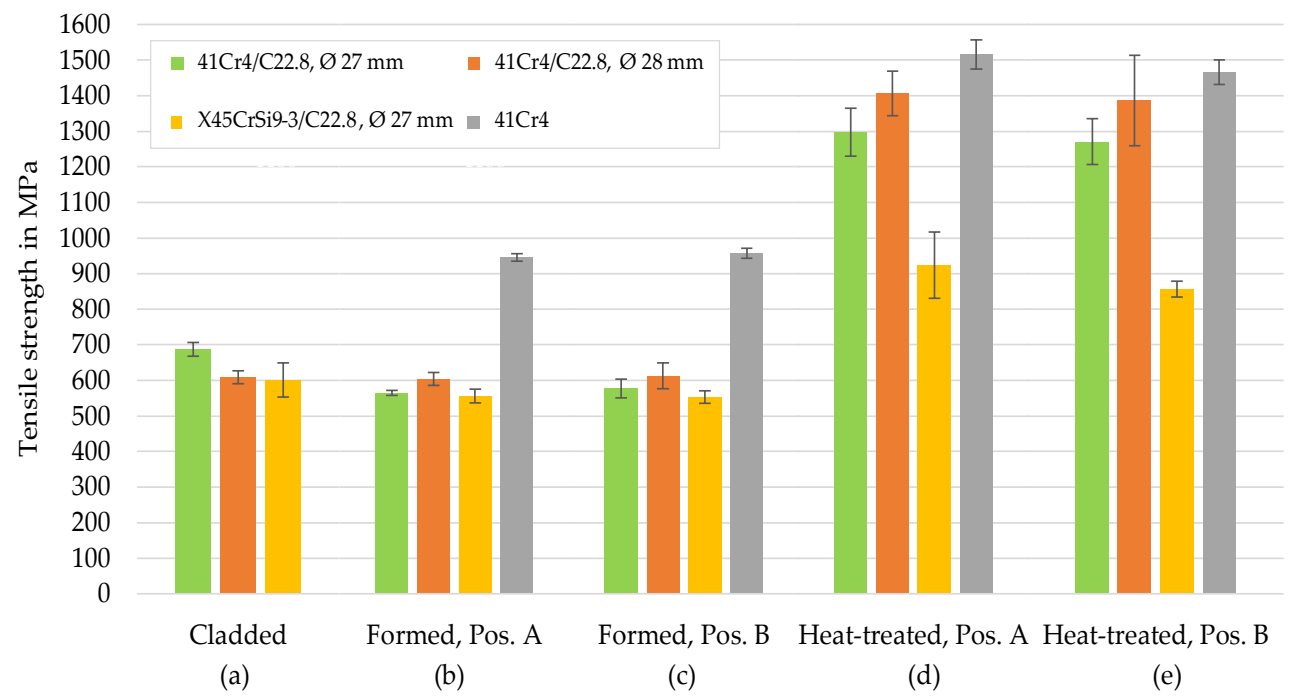

Figure 9. Tensile strength values of cladded workpieces (a), forged bevel gears at position A (b) and B (c), heat-treated bevel gears at position A (d) and B (e).

The integrated heat treatment increased the material strength as depicted in Figure 9d,e. In comparison to the condition after forging, the strength values of the samples of $41 \mathrm{Cr} 4 / \mathrm{C} 22.8$ (marked green and orange) doubled and were close to those of the steel $41 \mathrm{Cr} 4$. The samples of X45CrSi9-3/C22.8 show a lower strength. This can be attributed to higher self-tempering temperatures, and thus a lower hardness of the substrate and an increased hardness difference between cladding and substrate compared to 41Cr4/C22.8. Despite the microstructural differences at position A and B, the corresponding strength values do not differ substantially from each other.

\section{Discussion}

The previous methods for production of hybrid gears are generally represented by shrink fitting, friction welding [24] or bi-metal casting [25]. In the field of forging, there are only few investigations on the compound forging of straight bevel gears, where forming and the joining are combined in a single stage. The key challenge in joining by forming is the creation of the metallurgical bond between raw parts. Politics et al. studied the material flow behavior of different material combinations (steel-aluminum, steel-lead, steel-copper and copper-lead) depending on tooth ring thickness as well as friction properties in the interface zone and in the contact area between forging tool and workpiece [26,27]. Wu et al. carried out similar research for a steel-aluminum-combination focusing on gap size and height difference between ring and core [28]. In this context, the Tailored Forming technology using pre-joined workpieces represents an innovative approach for production of hybrid gears.

Each process step in the process chain of Tailored Forming contributes to the final quality of the bevel gear. The application of previously joined cladded workpieces ensures continuous joints and easy handling of multi-material workpieces throughout the whole process chain. The forging process after cladding facilitates a grain refinement of the coarse weld microstructure, which positively affects the mechanical properties of the parts. The heat treatment contributes to the functionality of the 
bevel gears under operating conditions by increasing strength and hardness values of the tooth flanks. The micrographs in Figure 8 illustrate the microstructural evolution along the process chain.

As revealed by the hardness measurements, heat treatment has the most decisive influence on the strength of cladding and substrate. The hardness increase in the substrate can be attributed to the fact that the investigated area was located in the heat-affected zone (HAZ) during the heat treatment (Figure 10). Due to different outer diameters of the bevel gears, tooth sizes and axial temperature gradients, the depths of the HAZ at positions A and B differ. For instance, the higher heat input to the gear core at position B results in prolonged surface cooling. Therefore, a shallower HAZ is observed at this position. Independent of the initial substrate diameter, the HAZ is of a similar thickness at both positions A (Figure 10a,c) and B (Figure 10b,d) for the material combination 41Cr4/C22.8. In the case of material combination $\mathrm{X} 45 \mathrm{CrSi}-3 / \mathrm{C} 22.8$, the size of the $\mathrm{HAZ}$ is reduced in comparison with $41 \mathrm{Cr} 4 / \mathrm{C} 22.8$ as a result of the different heat treatment strategy with higher self-tempering temperatures. At position B (Figure 10f), this effect is even more pronounced than at the position A due to the higher heat emanating from the bevel gear core.

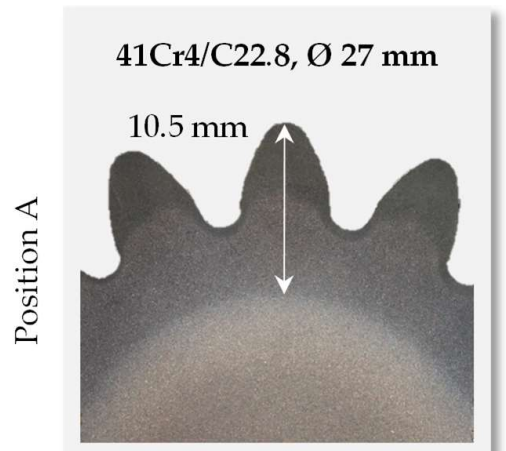

(a)

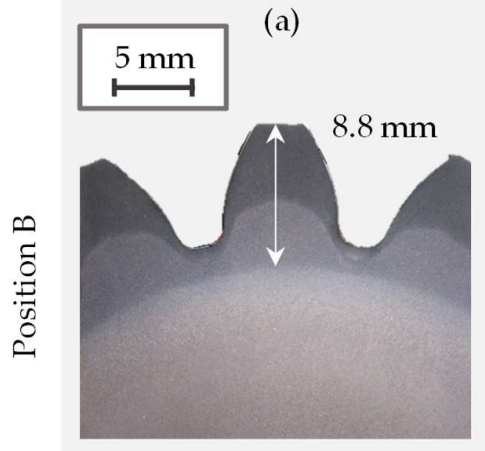

(b)

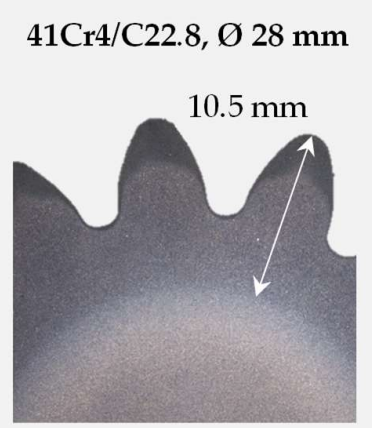

(c)

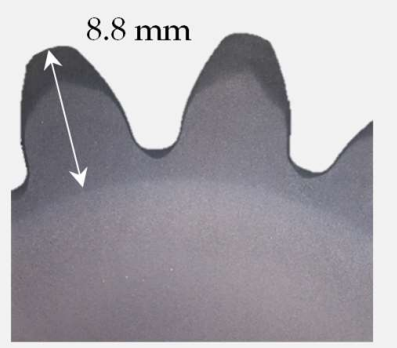

(d)

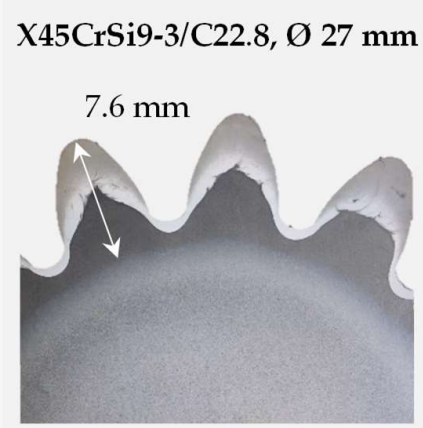

(e)

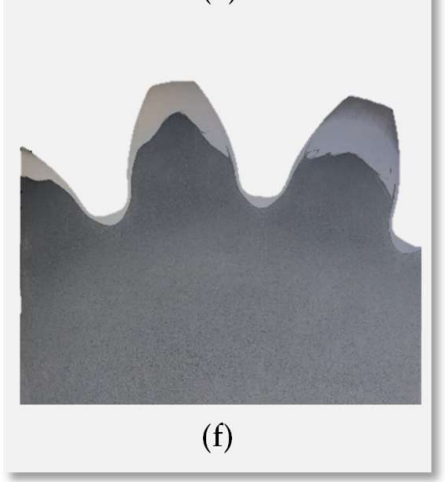

Figure 10. Heat-affected zones after quenching and self-tempering in bevel gears of the material combinations $41 \mathrm{Cr} 4 / \mathrm{C} 22.8(\mathbf{a}-\mathbf{d})$ and X45CrSi9-3/C22.8 $(\mathbf{e}, \mathbf{f})$ at position A $(\mathbf{a}, \mathbf{c}, \mathbf{e})$ and B $(\mathbf{b}, \mathbf{d}, \mathbf{f})$.

Comparing the tensile strength values of the bevel gears of material combination $41 \mathrm{Cr} 4 / \mathrm{C} 22.8$, the bevel gears with a substrate diameter of $28 \mathrm{~mm}$ show a higher strength after forging and heat treatment (Figure 9). Since the tensile specimens were prepared with the joining zone always located in the center of the specimens (Figure 7d), their extraction position from the bevel gears slightly differed due to a varying cladding layer thickness for $\varnothing 27 \mathrm{~mm}$ and $\varnothing 28 \mathrm{~mm}$. The tensile specimens for workpieces with an initial substrate diameter of $\varnothing 27 \mathrm{~mm}$ are slightly displaced in the direction of the tooth tip core. This results in a lower tensile strength compared to the $\varnothing 28 \mathrm{~mm}$ specimens (Figure 9b,c). With respect to heat treatment, the larger initial substrate diameter and the corresponding thinner cladding layer resulted in an increased hardening depth in the part of the tensile test specimens that corresponded to the substrate. Thus, a slightly higher tensile strength for the $\varnothing 28 \mathrm{~mm}$ specimens after quenching and self-tempering was observed (Figure $9 \mathrm{~d}, \mathrm{e})$. The lower tensile strength of the $\mathrm{X} 45 \mathrm{CrSi} 9-3 / \mathrm{C} 22.8$ bevel gears compared to those consisting of $41 \mathrm{Cr} 4 / \mathrm{C} 22.8$ 
results from the increased self-tempering temperatures, reducing strength in the C22.8 part of the tensile test specimens (cf. Figure 6). The heat in the component is therefore not dissipated as quickly as in the $41 \mathrm{Cr} 4 / \mathrm{C} 22.8$ bevel gears. Here, the increased self-tempering temperatures are intended to foster a secondary hardening by the formation of chromium carbides [29]. Self-tempering at higher temperatures and the lower heat dissipation result in a decreased hardness of the substrate (188/268 HV 0.5 for X45CrSi9-3/C22.8 compared to 340/410 HV 0.5 for 41Cr4/C22.8); cf. Table 2. Accordingly, the tensile strength of such specimens is reduced.

In future studies, the functionality of the investigated bevel gears will be tested under operating conditions. This will require a grinding of the tooth flanks in order to achieve a high meshing of the forged pinion with the mating gear. These experiments will provide information on the service life behavior of hybrid bevel gears of different material combinations and with varying cladding thicknesses and heat-treatment conditions.

\section{Conclusions}

In the present study, the process chain of Tailored Forming was used for producing high-performance hybrid bevel gears. The main results can be summarized as follows:

- The forming process has a great influence on the microstructure refinement. Due to the thermomechanical processing during forging, the initially coarse weld microstructure recrystallizes.

- The cooling strategy has the most important influence on the resulting values of hardness and tensile strength. High cooling rates by air-water spray quenching are the main strengthening factor. In air-cooled condition, hardness and strength remain almost unaffected.

- A process-integrated heat treatment by air-water spray quenching and self-tempering allows tailoring hardness and tensile strength in the cladding and the substrate.

- Since fracture of the hybrid tensile samples occurred in the lower strength substrate, a high quality of the bond at the interface was obtained.

- Hybrid bevel gears of the material combination 41Cr4/C22.8 manufactured by Tailored Forming feature a tensile strength similar to bevel gears of $41 \mathrm{Cr} 4$ mono-material.

- In comparison, bevel gears of the material combination $\mathrm{X} 45 \mathrm{CrSi} 9-3 / \mathrm{C} 22.8$ show a higher hardness in the cladding layer but a lower hardness in the substrate. While the increased hardness in the cladding is attributed to the formation of chromium carbides, the lower hardness in the substrate is caused by the increased self-tempering temperatures recommended for the steel grade $\mathrm{X} 45 \mathrm{CrSi}$ 9-3.

- The combination of Tailored Forming and a process-integrated heat treatment allows producing components with adapted hardness gradients by employing different materials and customized time-temperature profiles.

Author Contributions: Conceptualization, B.-A.B., A.C., J.D., C.K., S.H., F.N. and H.J.M.; investigation, A.C., J.D., C.K. and S.H.; writing-original draft preparation, B.-A.B., A.C., J.D., C.K., S.H., F.N. and H.J.M.; writing-review and editing, B.-A.B., A.C., J.D., C.K., S.H., F.N. and H.J.M.; visualization, A.C., J.D., C.K. and S.H.; supervision, B.-A.B., F.N. and H.J.M. All authors have read and agreed to the published version of the manuscript.

Funding: This research was funded by the Deutsche Forschungsgemeinschaft (DFG, German Research Foundation) grant number 252662854.

Acknowledgments: The results presented in this paper were obtained within the Collaborative Research Centre 1153 "Process chain to produce hybrid high-performance components by Tailored Forming" in subprojects A2 and B2. The authors would like to thank the subproject A4 (Alexander Barroi and Maximillian Mildebrath) for supplying cladded hybrid workpieces and the German Research Foundation (DFG) for the financial support of this project.

Conflicts of Interest: The authors declare no conflict of interest. 


\section{References}

1. Ashby, M.F. Multi-objective optimization in material design and selection. Acta Mater. 2000, 48, 359-369. [CrossRef]

2. Martinsen, K.; Hu, S.J.; Carlson, B.E. Joining of dissimilar materials. CIRP Ann. 2015, 64, 679-699.

3. Merklein, M.; Johannes, M.; Lechner, M.; Kuppert, A. A review on tailored blanks-Production, applications and evaluation. J. Mater. Process. Technol. 2014, 214, 151-164. [CrossRef]

4. Wang, S.; Liu, B.X.; Chen, C.X.; Feng, J.H.; Yin, F.X. Microstructure, mechanical properties and interface bonding mechanism of hot-rolled stainless steel clad plates at different rolling reduction ratios. J. Alloys Compd. 2018, 766, 517-526. [CrossRef]

5. Carradò, A.; Sokolova, O.; Ziegmann, G.; Palkowski, H. Press joining rolling process for hybrid systems. Key Eng. Mater. 2010, 425, 271-281. [CrossRef]

6. Behrens, B.-A.; Chugreev, A.; Matthias, T.; Poll, G.; Pape, F.; Coors, T.; Hassel, T.; Maier, H.J.; Mildebrath, M. Manufacturing and evaluation of multi-material axial-bearing washers by tailored forming. Metals 2019, 9, 232. [CrossRef]

7. Behrens, B.-A.; Sokolinskaja, V.; Chugreeva, A.; Diefenbach, J.; Thürer, S.; Bohr, D. Investigation into the bond strength of the joining zone of compound forged hybrid aluminium-steel bearing bushing. AIP Conf. Proc. 2019, 2113, 040028 .

8. Behrens, B.-A.; Bonhage, M.; Bohr, D.; Duran, D. Simulation Assisted Process Development for Tailored Forming. Mater. Sci. Forum 2019, 949, 101-111. [CrossRef]

9. Sun, C.Y.; Li, L.; Fu, M.W.; Zhou, Q.J. Element diffusion model of bimetallic hot deformation in metallurgical bonding process. Mater. Des. 2016, 94, 433-443. [CrossRef]

10. Kong, T.F.; Chan, L.C.; Lee, T.C. Qualitative study of bimetallic joints produced by solid state welding process. Sci. Technol. Weld. Join. 2008, 13, 679-682. [CrossRef]

11. Wohletz, S.; Groche, P. Temperature influence on bond formation in multi-material joining by forging. Procedia Eng. 2014, 81, 2000-2005. [CrossRef]

12. Förster, W.; Binotsch, C.; Awiszus, B. Process Chain for the Production of a Bimetal Component from Mg with a Complete Al Cladding. Metals 2018, 8, 97. [CrossRef]

13. Domblesky, J.; Kraft, F.; Druecke, B.; Sims, B. Welded preforms for forging. J. Mater. Process. Technol. 2006, 171, 141-149. [CrossRef]

14. Klotz, U.E.; Henderson, M.B.; Wilcock, I.M.; Davies, S.; Janschek, P.; Roth, M.; Gasser, P.; McColvin, G. Manufacture and microstructural characterisation of bimetallic gas turbine discs. Mater. Sci. Technol. 2005, 21, 218-224.

15. Bach, F.W.; Krause, C.; Behrens, B.-A.; Dahndel, H.; Huskic, A. Integration of heat treatment in precision forging of gear wheels. Arab. J. Sci. Eng. Sect. B Eng. 2005, 30, 103-112.

16. Puschmann, F.; Specht, E. Transient measurement of heat transfer in metal quenching with atomized sprays. Exp. Therm. Fluid Sci. 2004, 28, 607-615. [CrossRef]

17. Krause, C.; Wulf, E.; Nürnberger, F.; Bach, F.W. Wärmeübergangs-und Tropfencharakteristik für eine Spraykühlung im Temperaturbereich von 900-100 C. Forsch. IM Ing. 2008, 72, 163-173. [CrossRef]

18. Behrens, B.-A.; Bistron, M.; Küper, A. Investigation of load adapted gears and shafts manufactured by compound-forging. J. Adv. Manuf. Syst. 2008, 7, 175-182. [CrossRef]

19. Behrens, B.-A.; Diefenbach, J.; Chugreeva, A.; Kahra, C.; Herbst, S.; Nürnberger, F. Tailored Forming of Hybrid Bevel Gears with Integrated Heat Treatment. Procedia Manuf. 2020, 47, 301-308.

20. Rudnev, V.; Loveless, D.; Cook, R.L. Handbook of Induction Heating; CRC Press: London, UK, 2017.

21. Herbst, S.; Steinke, K.F.; Maier, H.J.; Milenin, A.; Nürnberger, F. Determination of heat transfer coefficients for complex spray cooling arrangements. Int. J. Microstruct. Mater. Prop. 2016, 11, 229-246. [CrossRef]

22. EN ISO 6507-1: Metallic Materials_Vickers Hardness Test_Part 1: Test Method; International Organization for Standardization: Geneva, Switzerland, 2005.

23. EN ISO 6892-1: Metallic Materials-Tensile Testing-Part 1: Method of Test at Room Temperature; International Organization for Standardization: Geneva, Switzerland, 2005.

24. Wadleigh, A.S. Multi-Metal Composite Gear/Shaft-Produced by Consecutively Forming, Friction Welding, Reforming and Friction Welding, then Machining Three Elements of Dissimilar Metals. U.S. Patent No. 5492264, 20 February 1996. 
25. Miller, W.H. Gear Blanks. U.S. Patent No. 3847557, 12 November 1974.

26. Politis, D.J.; Lin, J.; Dean, T.A. Investigation of material flow in forging bi-metal components. Steel Res. Int. 2012, 231, 234.

27. Politis, D.J.; Lin, J.; Dean, T.A.; Balint, D.S. An investigation into the forging of Bi-metal gears. J. Mater. Process. Technol. 2014, 214, 2248-2260. [CrossRef]

28. Wu, P.; Wang, B.; Lin, J.; Zuo, B.; Li, Z.; Zhou, J. Investigation on metal flow and forming load of bi-metal gear hot forging process. Int. J. Adv. Manuf. Technol. 2017, 88, 2835-2847. [CrossRef]

29. Deng, H.X.; Shi, H.J.; Tsuruoka, S.; Yu, H.C.; Zhong, B. Influence of Heat Treatment on Characteristic Behavior of Co-Based Alloy Hardfacing Coatings Deposited by Plasma Transferred Arc Welding. Key Eng. Met. 2011, 462, 593-598. [CrossRef]

(C) 2020 by the authors. Licensee MDPI, Basel, Switzerland. This article is an open access article distributed under the terms and conditions of the Creative Commons Attribution (CC BY) license (http://creativecommons.org/licenses/by/4.0/). 